\title{
Serological survey of Leishmania infection in blood donors in Salvador, Northeastern Brazil
}

\author{
Kiyoshi F Fukutani ${ }^{1}$, Virgínia Figueiredo ${ }^{2}$, Fabiana S Celes ${ }^{1}$, Juqueline R Cristal ${ }^{1}$, Aldina Barral ${ }^{1,3}$, \\ Manoel Barral-Netto ${ }^{1,3}$ and Camila I de Oliveira ${ }^{1,3^{*}}$
}

\begin{abstract}
Background: Visceral Leishmaniasis is endemic to Brazil, where it is caused by Leishmania infantum (syn. Leishmania chagasi). Following parasite inoculation, individuals may experience asymptomatic infection, raising the possibility of parasite transmission through the transfusion of contaminated blood products. In the present work, we evaluated the prevalence of asymptomatic Leishmania infection among blood donors in Salvador, northeastern Brazil.

Methods: Peripheral blood was collected from 700 blood donors attending the Blood Bank of Bahia (HEMOBA/ SESAB), from January to September 2010. We evaluated anti-Leishmania serology by ELISA, employing Soluble Leishmania Antigen (sensitivity $90 \%$ and specificity 95\%). The presence of parasite DNA was determined by qPCR, targeting a single copy gene (G6PD), and by end-point PCR, targeting multiple targets, namely a segment located in the Leishmania rRNA locus (ITS) and the conserved region of kinetoplastid DNA (KDNA) minicircles.

Results: The blood-donor population was comprised of $74.5 \%$ of males with a mean age of 34 years. Anti-Leishmania serology by ELISA was positive in 5.4\% (38/700) individuals. One individual was also positive for Chagas' disease and another tested positive for Syphilis. Employing qPCR, parasite DNA was not found in any of 38 seropositive samples. However, by ITS PCR, 8/38 (21\%) samples were positive and this positivity increased to 26/38 (68\%) when we targeted kDNA amplification. Agreement between both techniques (ITS and kDNA PCR) was fair ( $k a p p a=0.219$ ).
\end{abstract}

Conclusions: These results indicate that asymptomatic infection is present among the blood donor population of Salvador, a finding that warrants a broader discussion regarding the need to implement specific screening strategies.

Keywords: Leishmania, Blood supply, Asymptomatic infection, PCR, ELISA

\section{Background}

Visceral leishmaniasis (VL) or kalazar is a serious public health problem worldwide, and approximately 500,000 new cases are reported each year $\{[1] \# 67\}$. Leishmania infantum is the causative agent of VL in Brazil, which accounts for $90 \%$ of cases in the Americas $\{[2] \# 257\}$ and where 3392 VL cases were reported in 2012 \{[3], $\# 258$ \}. In the last decades, VL is becoming more prevalent in urban centers of Brazil, especially in expanding cities with different patterns of economic and social development \{[4] \#259\}. Patent VL is classically characterized by the presence of irregular fever, paleness, and splenomegaly and, in the absence of treatment; it is a

\footnotetext{
* Correspondence: camila@bahia.fiocruz.br

${ }^{1}$ Centro de Pesquisas Gonçalo Moniz, Fundação Oswaldo Cruz (FIOCRUZ), Rua Waldemar Falcão, 121, Salvador, BA, Brazil

${ }^{3}$ Instituto de Investigação em Imunologia, Salvador, BA, Brazil

Full list of author information is available at the end of the article
}

progressive infection with fatal outcome $\{[3]$ \#279\}. However, a large number of infections remain asymptomatic, in which individuals are infected by Leishmania but display an apparent healthy condition (rev. in \{[5] \#260\}). There are concerns that asymptomatic individuals remain carriers of the infection and, as such, may play an important role in the epidemiology of VL, especially in urban concentrations where the disease is present $\{[6] \# 261\}$.

Classically, transmission of Leishmania parasites occurs through sand fly bites, however, studies in France $\{[7] \# 248\}$, Italy $\{[8] \# 6\}$, Spain $\{[9] \# 12\}$, India $\{[10] \# 9\}$, Bangladesh $\{[11] \# 250\}$ and Turkey $\{[12] \# 251\}$ showed that asymptomatic individuals are found among blood donors, suggesting that transfusion of Leishmania-contaminated blood products might be a source of disease transmission in parallel to syringe sharing $\{[13] \# 68\}$ and 
organ transplantation $\{[14]$ \#7; [15] \#8; [16] \#19; [17] \#41; [18] \#246\}. In northeastern Brazil, the prevalence of anti-Leishmania antibodies was 9\% among blood donors, increased to $25 \%$ in a VL focus and was highest (37\%) among poly-transfused hemodialysis patients $\{[19] \# 37\}$. In a subsequent study, upon evaluation of 21 seropositive blood-donors, authors found that five individuals (23\%) were positive to Leishmania by PCR whereas dot-blot hybridization increased this positivity to nine individuals $(43 \%)\{[20] \# 10\}$. In central western Brazil, the prevalence of anti-Leishmania antibodies among a population of blood donors was reported at $15.6 \%\{[21]$ \#262\}, indicating the presence of asymptomatic individuals among blood donors in different regions of the country.

Herein, our goal was to determine the prevalence of anti-Leishmania antibodies among blood donors of Salvador, Bahia, situated in northeastern Brazil. Although Salvador city per se is not endemic for VL, the HEMOBA/SESAB central blood bank draws donors from all over Bahia state and, as such, consists of a primordial sample for large-scale investigation. Of note, Bahia accounted for $\sim 8 \%$ of VL cases registered in Brazil in 2012 and in 2013 \{[22], \#258\}. We investigated both the presence of anti-Leishmania antibodies and of parasite DNA. For the latter, we employed a quantitative Real Time PCR (qPCR) $\{[23] \# 24\}$, targeting a single copy gene, and two conventional (end-point) PCR assays targeting: i) the Internal Transcribed Spacers present in rRNA $\{[24] \# 252\}$ and ii) the conserved region of minicircle $\mathrm{kDNA}\{[25] \# 253\}$.

\section{Methods}

\section{Ethical considerations}

This study was approved by the research ethics committee of CPqGM-FIOCRUZ-BA (No. 215/2010). Individuals involved in this study were required to sign the Informed Consent Form.

\section{Study design and population}

The purpose of this study was to identify asymptomatic infection in blood donors attending the Hematology and Hemotherapy Foundation of Bahia State (HEMOBA/ SESAB), situated in Salvador, BA, Brazil. The necessary sample size of approximately 220 individuals was estimated according to the following parameter: prevalence of an asymptomatic infection rate of $9 \%$, based on a study conducted in Natal $\{[19] \# 37\}$, a VL endemic area $\{[26] \# 254\}$. Blood was obtained from 700 donors attending HEMOBA/SESAB and blood donations were screened over a period of nine months (January to September 2010). Donors resided in Salvador and other municipalities from BA.

\section{Sample collection}

Whole blood was collected in quadruple blood packs (Fresenius/KAB), using the top-and-bottom system. Aliquots of $5 \mathrm{ml}$ of peripheral blood were obtained following blood collection and were placed into Vacutainer ${ }^{\circ}$ tubes (Becton Dickinson) containing Heparin as anticoagulant. Serum was separated by centrifugation and stored at $-20^{\circ} \mathrm{C}$ for subsequent serologic studies. Aliquots of $200 \mu \mathrm{l}$ of blood were used for DNA extraction.

\section{Soluble Leishmania antigen}

SLA was prepared from L. infantum MCAN/BR/00/ BA262) and from L. amazonensis (MHOM/BR/1985/ BA32) promastigotes maintained in Schneider (LGC Scientific) medium (Sigma) supplemented with $10 \%$ inactivated fetal bovine serum, $100 \mathrm{U} / \mathrm{ml}$ penicillin and 100 $\mathrm{ug} / \mathrm{ml}$ streptomycin (Life Technologies). The parasites were initially submitted to 10 alternating cycles of freezing in liquid nitrogen and thawing in a water bath and were then centrifuged at $1600 \times \mathrm{g}, 4^{\circ} \mathrm{C}$ for $15 \mathrm{~min}$. The supernatant containing SLA was collected and protein content was quantified using the Micro BCA TM Protein Reagent Kit assay (Pierce).

\section{ELISA to detect anti-Leishmania antibodies}

Anti-Leishmania serology was performed by ELISA, as described $\{[27] \# 20\}$. Briefly, 96-well plates (Linbro/ Titertek) were coated with $10 \mu \mathrm{g} / \mathrm{mL}$ of antigen $(L$. infantum or L. amazonensis SLA) and were incubated overnight at $4^{\circ} \mathrm{C}$. After three washes with $\mathrm{PBS} / 0.5 \%$ Tween, plates were blocked for 1 hour at $37^{\circ} \mathrm{C}$ with $\mathrm{PBS} /$ Tween $0.5 \%$ plus $1 \%$ fetal bovine serum (FBS) (Life Technologies). Plasma samples, diluted 1:100 in PBS/ Tween $0.5 \%$ plus $1 \%$ FBS were added in duplicate and plates were incubated for 2 hours at room temperature. After three rounds of washing, wells were incubated with anti-human IgG conjugated to alkaline phosphatase (SIGMA) at a 1:2500 dilution in PBS/Tween 0.5\% plus $1 \%$ FBS for 1 hour at room temperature. Plates were then washed and were further incubated for 30 minutes with a chromogenic solution of p-nitrophenyl phosphate (SIGMA) in sodium carbonate buffer $\mathrm{pH} 9.6$ containing $1 \mathrm{mg} / \mathrm{mL}$ of $\mathrm{MgCl}_{2}$. In all experiments, the values obtained were subtracted from those obtained in the background. ELISA experiments were repeated twice yielding similar results. The ELISA cut-off value for $L$. infantum and L. amazonensis SLA was established using ROC curves (please see Statistical analysis below). In this case, we employed a panel of positive sera $(n=20)$, obtained from VL patients [defined by clinical and laboratory signs $\{[28] \# 280\}$ and a positive bone marrow aspirate]. Control sera $(n=20)$ were obtained from negative individuals, living in areas free of $L$. infantum. These 
sera were randomly selected from a serum bank (LIPCPqGM-FIOCRUZ).

\section{DNA extraction}

DNA was extracted from $200 \mu \mathrm{L}$ of whole blood using Illustra Genomic Prep Blood Mini Spin Kit ${ }^{\text {tw }}$ (GE Healthcare), following the manufacturer's instructions. DNA was eluted into $200 \mu \mathrm{L}$ of Elution buffer and stored at $-20^{\circ} \mathrm{C}$. Purity of genetic material was assessed by absorbance at $260 / 280 \mathrm{~nm}$.

\section{Real-Time PCR}

Detection of Leishmania DNA by Real Time PCR was performed as described by $\{[23] \# 24\}$. Briefly, real time PCR was conducted in an ABI PRISM ${ }^{\circ} 7500$ Sequence Detection System (Applied Biosystems) employing SYBRGreen ${ }^{\circ}$ PCR Master Mix (Invitrogen), 50 ng DNA and $200 \mathrm{nM}$ of each forward and reverse primers. Thermal cycle conditions consisted of a denaturation step at $95^{\circ} \mathrm{C}$ for 10 minutes followed by 40 cycles at $95^{\circ} \mathrm{C}$ for 15 seconds and $60^{\circ} \mathrm{C}$ for 1 minute. Oligonucleotides (Fwd G6PD 5'CCCGAGGGCAGCACTTG-3' and Rev G6PD 3'-CCAC CGGTCGTTGTTGATG-5') were designed using PrimerExpress3.0 (Applied Biosystems) and were based on the $L$. infantum G6PD gene (glucose-6-phosphate dehydrogenase) (GeneBank: DQ212794.1). For parasite quantification, a standard curve was constructed based on DNA extracted from serial dilutions of L. infantum, ranging from $10^{6}$ to $10^{1}$ parasites. Analysis and acquisition of data were performed with SDS software (Applied Biosystems).

\section{Conventional PCR}

End-point PCR targeting the 120-bp conserved region of the Leishmania kDNA minicircles $\{[25] \# 253\}$ was performed as described $\{[29] \# 264\}$, employing primers $5^{\prime}$ GGG (G/T)AGGGGCGTTCT(G/C)CGAA-3' and $5^{\prime}$-(G/C) $(\mathrm{G} / \mathrm{C})(\mathrm{G} / \mathrm{C})(\mathrm{A} / \mathrm{T}) \mathrm{CTAT}(\mathrm{A} / \mathrm{T}) \mathrm{TTACACCAACCC} \mathrm{C-3'.} \mathrm{The}$ second end-point PCR assay targeted amplification of the segment containing ITS 1,2 and the $5.8 \mathrm{~S}$ region, within the rRNA gene locus \{[24] \#252\}. Primers employed were IR1 (5'-GCTGTAGGTGAACCTGCAGCA GCTGGATCATT-3') and IR2 (5'-GCGGGTAGTCCTG CCAAACACTCAGGTCTG-3'). Reactions were performed in a final volume of $20 \mu \mathrm{l}$, with $50 \mathrm{ng}$ of DNA, $0.2 \mu \mathrm{M}$ of each oligonucleotide and PCR supermix (Invitrogen), following manufacturer's instructions. PCR conditions were as follows: denaturation at $94^{\circ} \mathrm{C}$ for $3 \mathrm{~min}$, followed by 30 cycles of $94^{\circ} \mathrm{C}$ for $60 \mathrm{sec}, 55^{\circ} \mathrm{C}$ for $60 \mathrm{sec}$ and $94^{\circ} \mathrm{C}$ for $120 \mathrm{sec}$ with a final extension of $72^{\circ} \mathrm{C}$ for $10 \mathrm{~min}$. The amplification reactions were analyzed by agarose gel electrophoresis, followed by silver or ethidium bromide staining. DNA from the reference $L$. infantum strain was used as positive control for PCR reactions.

\section{Statistical analysis}

Statistical analysis was performed using Prism v.5.0 (Graph Pad Software). ROC (Receiver Operating Characteristic) curves were calculated based on ELISA assays performed with SLA obtained from L. amazonensis and L. infantum. The cut-off, as determined by high sensitivity and specificity, from the highest probability of discrimination established by the curve, was therefore determined. The performance of each SLA was established by the parameters obtained from ROC curves values (AUC, $p$ values and likelihood ratio). Nonparametric Mann-Whitney test was used to compare the frequency of seropositive individuals with a positive PCR result or a negative PCR result. The $p$ value was considered significant when $<0.05$. Agreement between PCR assays targeting Leishmania ITS and kDNA were determined by the kappa index.

\section{Results}

\section{Anti-L. infantum serology in blood donors recruited at} HEMOBA/SESAB

Initially, we determined the sensitivity and specificity of the Soluble Leishmania Antigen (SLA) preparations [obtained from $L$. infantum or from $L$. amazonensis (the latter an etiological agent of Cutaneous Leishmaniasis)] when employed as the capture antigen in ELISA assays. With the results obtained, we constructed two ROC curves (Figure 1). L. infantum SLA performed better (AUC: 0.99, p < 0.0001, Likelihood ratio: 18.0) (Figure 1) when compared to L. amazonensis SLA (AUC 0.87; $\mathrm{p}<$ 0.0001 and Likelihood Ratio 15.0). Therefore, SLA from L. infantum presented higher sensitivity and specificity when compared to SLA from L. amazonensis and was selected for subsequent experiments. The cut off value, based on higher sensitivity and specificity of L. infantum SLA, was established as 0.01685 .

\section{Cross-reaction among Leishmania and other blood borne pathogens}

Next, we investigated the presence of anti-Leishmania antibodies in the sera from 700 blood donors $(74.5 \%$ male) attending HEMOBA/SESAB. The median age was 42 years: $31.7 \%$ individuals had between 19 and 28 years, $32.8 \%$ between 28 and 38 years, and 34\% were older than 38 years of age. The reactivity of blood donors' sera to L. infantum SLA was significantly higher compared to that obtained with negative controls (Figure 2). As expected, the reactivity of sera from confirmed VL patients was higher $(\mathrm{p}<0.0001)$ compared to both blood donors and negative controls (Figure 2). Among the blood donors, we identified 38 individuals (5.4\%) (81.5\% male) that reacted above the established cut-off value $(0.01685)$ and were thus considered seropositive against $L$. infantum. These 38 samples were also tested for cross-reactivity to 


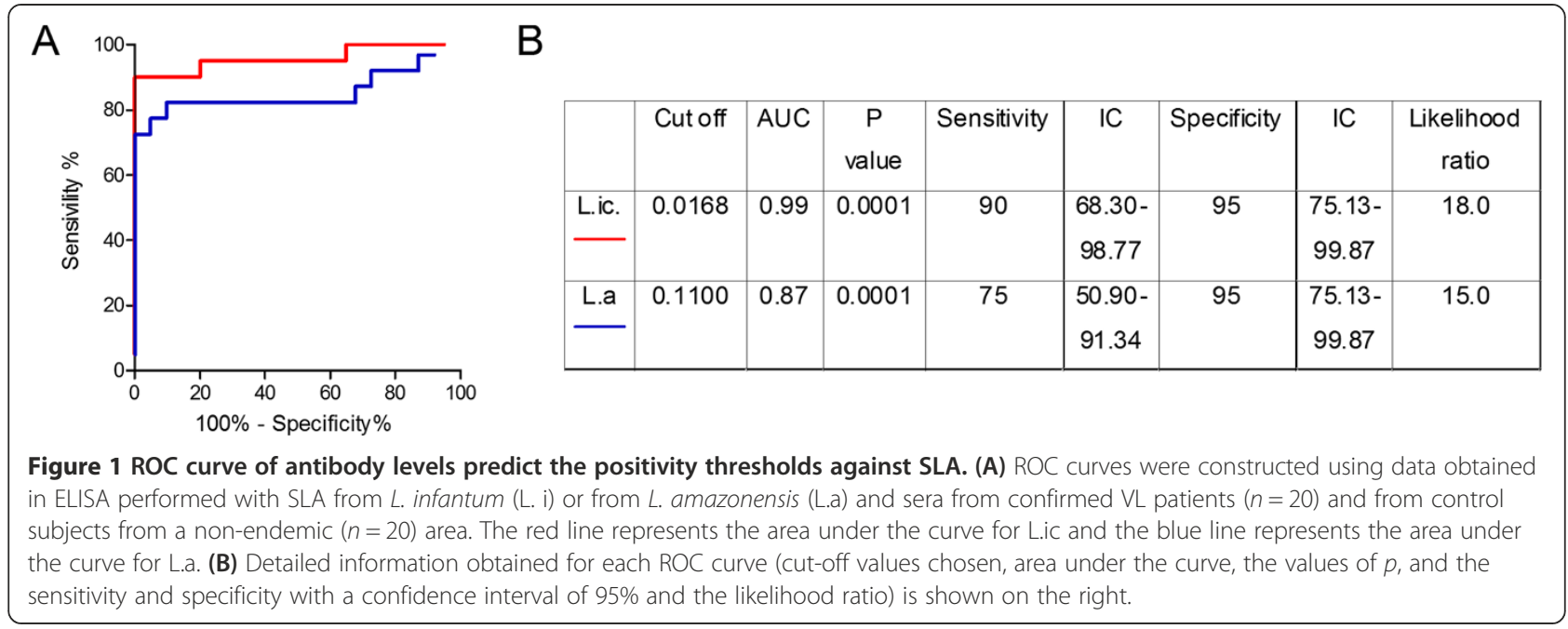

other agents, following the routine blood screening investigation performed at HEMOBA/SESAB. Among the 38 Leishmania seropositive samples, $1 / 38(0.02 \%)$ reacted positive for Chagas' disease whereas another sample $(1 / 38)$ reacted positively for Syphilis. Of note, among the 38 blood donors that were seropositive for Leishmania, 26/38 (68\%) currently live in Salvador whereas 8/38 (21\%) live in adjacent municipalities (address information was missing from four samples).

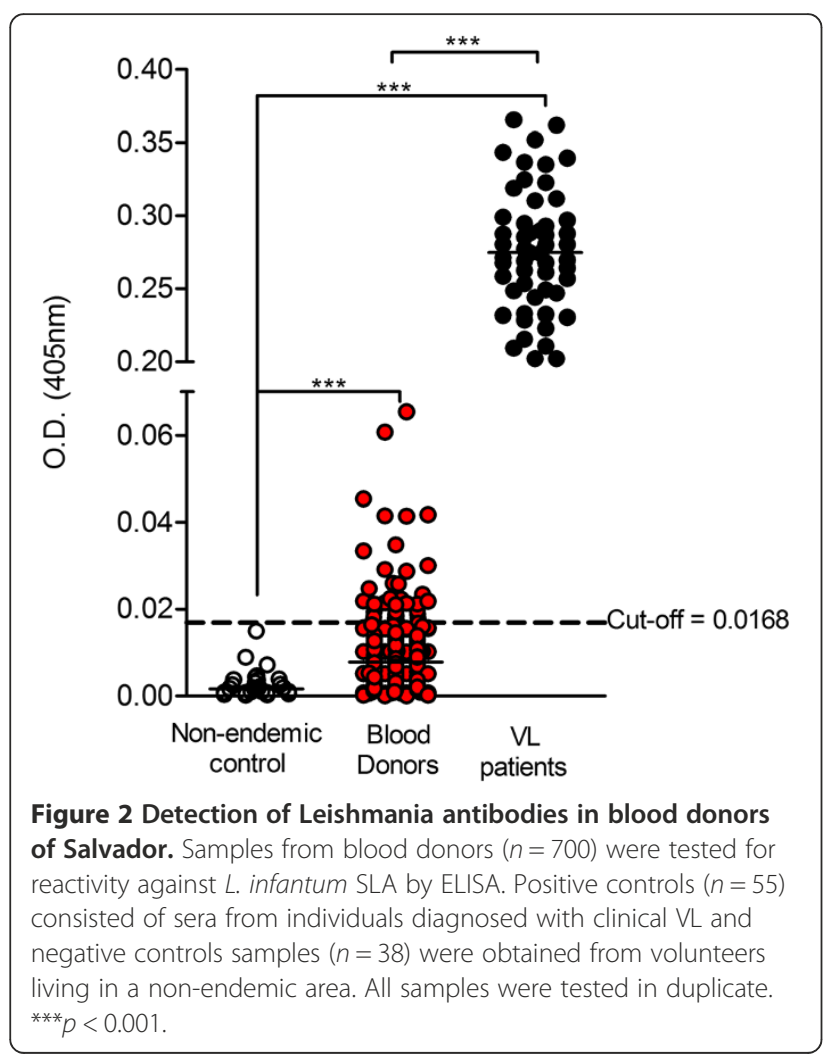

Detection of Leishmania DNA in blood donors' samples We then investigated the parasite load in the 38 (5.4\%) Leishmania seropositive samples (Figure 2). To do so, DNA extracted from the 38 blood samples was submitted to quantitative PCR (qPCR) targeting the single copy G6PD gene $\{[30] \# 243\}$. A standard curve (threshold cycle versus logarithm of the amplicon copy number) was constructed using DNA extracted from L. infantum, ranging $10^{6}$ to $10^{1}$ parasites (Figure 3). The standard curve showed a good linear correlation $\left(R^{2}=0.971\right)$ when plotted against the DNA equivalent to the number of parasites and the efficiency of the assay was $97 \%$. We did not detect any level of interference due to the presence of human DNA as a similar efficiency of amplification was obtained when standard curves were generated from parasite DNA spiked with human DNA or from DNA extracted from a mixture of parasites plus human DNA (data not shown). Using the G6PD qPCR assay, we were not able to detect Leishmania DNA in any of the 38 blood donors that were seropositive by ELISA (Table 1). We then investigated whether end-point PCR assays targeting multiple copy genes would improve detection of parasite DNA. Targeting the region located between the small and the large subunit of the Leishmania rRNA gene array, including the Internal Transcribed Spacers (ITS) and the 5.8S rRNA $\{[24] \# 252\}$, we detected positive amplification in $8 / 38(21.0 \%)$ samples (Table 1). In another assay, we amplified the conserved region of minicircles, present in 10,000-20,000 copies, located within the Leishmania kinetoplast \{[25] $\# 253\}$. This assay was positive in $26 / 38$ (68.4\%) samples (Table 1), raising the detection level by $47,4 \%$ when compared to ITS PCR (Table 1). The concordance between kDNA and ITS PCR was fair $(k a p p a=0.219)$ (Table 2). Lastly, positivity in either PCR assays, ITS or kDNA amplification, was dissociated from serology 


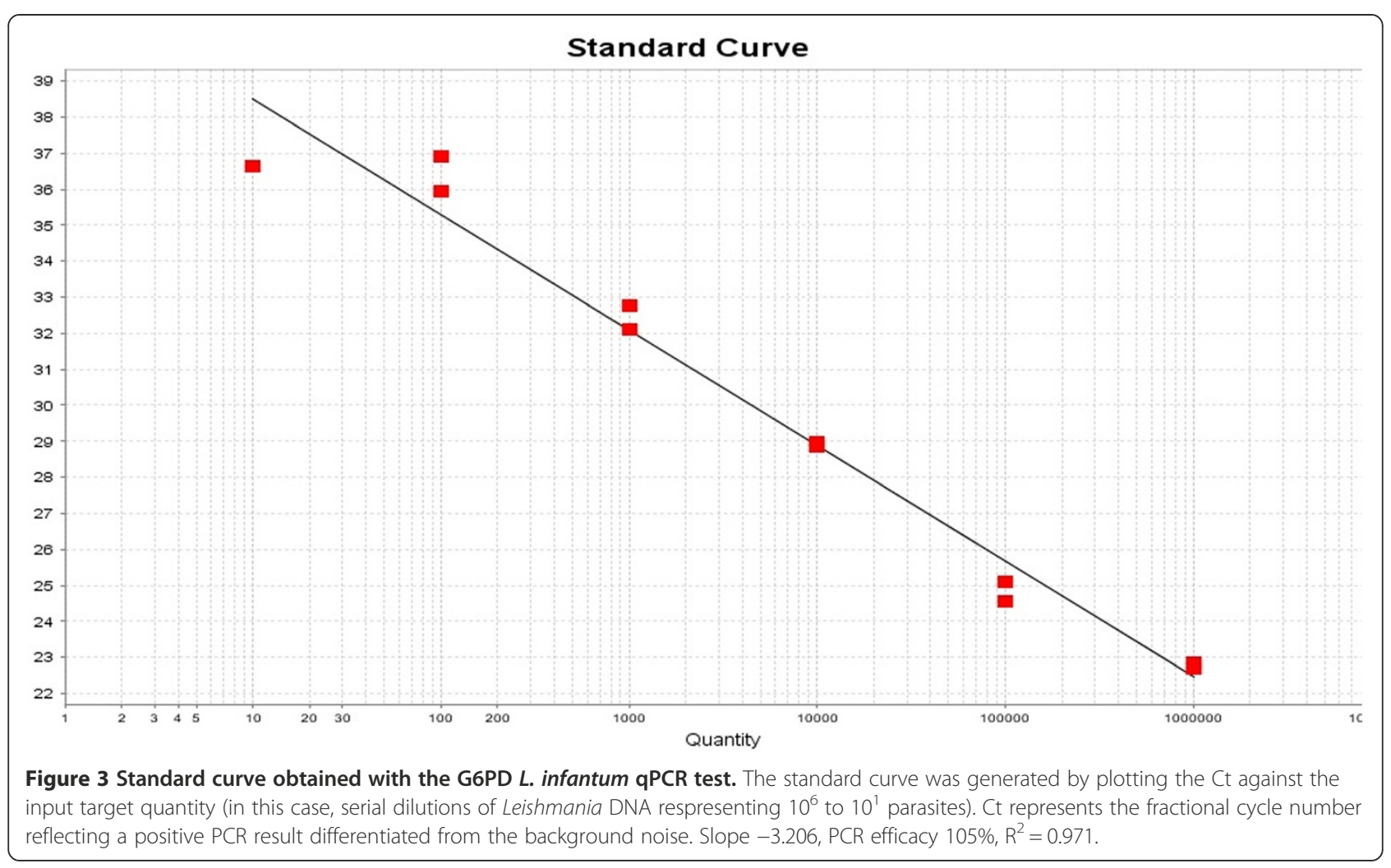

OD levels, determined by ELISA (Figure 4A and B, respectively).

\section{Discussion}

Asymptomatic Leishmania infantum infection can be detected initially with antibodies $\{[31] \# 275\}$; antibody responses decline with time in parallel to the development of a cell mediated immune response \{[32] \#282\}. Therefore, serologic responses to Leishmania indicate acute infection, in the presence of symptoms or not. Reports of Leishmania transmission through the use of contaminated blood products $\{[14] \# 7$; [10] \#9\} have raised the question whether asymptomatic infection among blood donors poses a problem for the blood supply, especially in regions where VL is endemic. Presently, we investigated the anti-Leishmania serologic response among blood donors from Salvador, northeastern Brazil. Additionally, we employed three PCR-based assays to determine the presence of Leishmania DNA in samples with positive serology.

Table 1 Detection of Leishmania DNA in blood donors ( $n=38$ ) from Salvador, seropositive for Leishmania

\begin{tabular}{llll}
\hline PCR & G6PD $\{[\mathbf{3 0}]$ \#243\} & ITS $\{[\mathbf{2 4 ]}$ \#252\} & kDNA \{[25] \#253\} \\
\hline Positive, $n(\%)$ & 0 & $8(21.1)$ & $26(68.4)$ \\
Negative, $n(\%)$ & $38(100)$ & $30(78.9)$ & $12(31.6)$ \\
Total & 38 & 38 & 38 \\
\hline
\end{tabular}

Among the 700 blood donors recruited at HEMOBA/ SESAB, the major blood donation center in Salvador, we detected 38 individuals (5.4\%) with a positive serology to Leishmania. This finding is similar to that reported in Montes Claros (5.5\%) \{[33] \#265\} but lower than that observed in Natal (9\%) $\{[20] \# 10\}$ and in Campo Grande (15.6\%) $\{[21] \# 262\}$, both of which are endemic regions for $\mathrm{VL}$. The lower prevalence detected in our study may be due to the fact that Salvador is not a VL endemic area per se, differently from the other three municipalities. Additionally, differences in the sensitivity of the tests employed herein (SLA-based ELISA) versus those used in Natal (FML-ELISA) $\{[20] \# 10\}$, Montes Claros and Campo Grande (IFAT) $\{[33] \# 265$; [21] \#262\} may contribute for the differing results. In our study, an ELISA assay employing $L$. amazonensis SLA was less sensitive when compared to L. infantum SLA (Figure 1), suggesting that the choice of antigen impacts on the results

Table 2 Agreement between kDNA and ITS PCR results in blood donors $(n=38)$ with anti-Leishmania antibodies

\begin{tabular}{llll}
\hline & \multicolumn{2}{l}{ kDNA } & \\
\cline { 2 - 3 } ITS & Positive (\%) & Negative (\%) & Total \\
\hline Positive, $\mathrm{n}(\%)$ & $8(21)$ & 0 & 8 \\
Negative, $\mathrm{n}(\%)$ & $18(47)$ & $12(31)$ & 30 \\
Total & 26 & 12 & 38 \\
\hline
\end{tabular}

Kappa $=0.219$. 


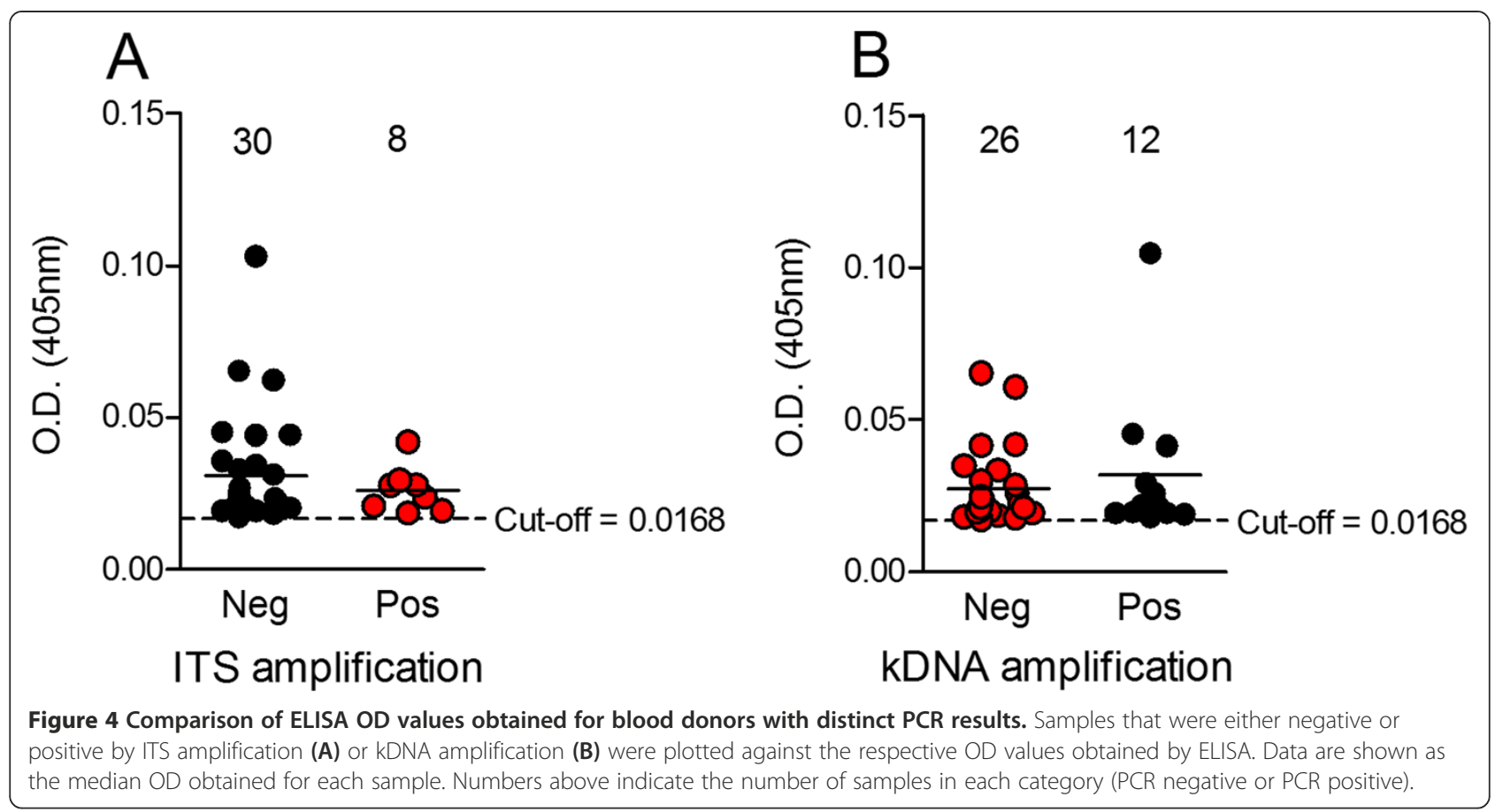

obtained. Among the 38 seropositive individuals detected herein, only one tested positive for Chagas disease under the routine screening performed at HEMOBA. We suggest that, in this current setting, routine screening for Chagas' disease is not excluding Leishmania infection.

Molecular techniques have been successfully used to detect asymptomatic Leishmania infection \{[34] \#28; [26] \#254; [35] \#40; [36] \#272\} \{[37] \#273\} and for the diagnosis and follow-up of VL patients $\{[38] \# 266$; [39] \#267\}. Herein, we employed PCR to detect parasite DNA in the 38 individuals presenting anti-Leishmania antibodies. A quantitative assay, based on amplification of a single-copy target $(G 6 P D)\{[30] \# 243\}$, failed to amplify parasite DNA within the range established by the standard curve. This assay, however, was successful at identifying and estimating the number of parasites in biopsy samples from Cutaneous Leishmaniasis patients $\{[30] \# 243\}$. One possible reason can be the presence of very low levels of circulating parasites, hampering amplification of a single-copy gene. However, in a study conducted in Natal state, Brazil, positivity by qPCR (17\%) was lower compared to positivity by ELISA (24.6\%), even when a repetitive region was used as the amplification target $\{[26] \# 254\}$. In Minas Gerais state, Brazil, authors detected 56.5 parasites $/ \mathrm{ml}$ of blood from seropositive individuals and this rate decreased to 7.8 parasites $/ \mathrm{ml}$ after a one-year follow up, as measured by qPCR also targeting a repetitive region $\{[40] \# 270\}$. Indeed, a number of studies have reported differences in positivity by serological and molecular tests to detect Leishmania \{[41]
\#31; [20] \#10; [42] \#255, [43] \#13 [11] \#250\}. Herein, when we employed conventional end-point PCR targeting the ITSs within the rRNA gene array $\{[24] \# 252\}$ or the conserved region within kDNA minicircles \{[25] $\# 253$, we were able to amplify Leishmania DNA in $8 / 38$ (21\%) and 28/38 (68\%) seropositive samples, respectively, and agreement between both techniques was fair $($ kappa $=0.219)$. In a study with HIV/AIDS patients, prevalence of Leishmania based on ITS PCR was $1.8 \%$ $\{[44] \# 268\}$ whereas by kDNA PCR, it increased to $11.8 \%$, in France $\{[41] \# 31\}$, to $24 \%$ in Spain $\{[42] \# 255\}$ and to $36.4 \%$ in Italy $\{[43] \# 14\}$. These results are in accordance with our observation that the higher the number of repetitions of a given amplification target, such as the ITSs or kDNA, the higher the sensitivity of the assay $\{[45] \# 278\}$. In our hands, kDNA amplification also proved a useful tool for the diagnosis of Cutaneous $\{[29]$ \#264\} and Mucocutaneous Leishmaniasis \{[46] \#281\}. The fact that either ITS or kDNA amplification was negative in 12/38 samples (31.6\%) with a positive Leishmania serology could again be explained by the presence of very low parasite numbers and, hence, few targets were available for PCR amplification. Another hypothesis is the presence of parasite remnants within phagocytic cells, rendering a positive amplification of Leishmania DNA by PCR.

In the current setting, blood screening for the presence of VL would decrease blood supply by $5 \%$, negatively impacting on the blood supply provided by HEMOBA/SESAB. Hamsters transfused with blood from an experimentally infected animal developed disease as 
shown by presence of ascites, cachexia and death \{[47] \#44\}. Foxhounds that received packed red blood cell transfusions from seropositive donors also tested positive for Leishmania antibodies $\{[48] \# 43\}$, indicating transmission of Leishmania to recipient dogs by blood transfusion. In a study conducted in Bangladesh, 1.195 blood donors were screened, antibodies were found in three individuals but none developed VL during a 6 month follow-up period $\{[11] \# 250\}$, suggesting that the number of circulating parasites is below the threshold necessary to initiate symptoms.

\section{Conclusions}

Given that positive serology and/or presence of parasite DNA does not guarantee transfusional risk, the importance of our results lies in the recognition of the presence of cryptic Leishmania infection among blood donors from Salvador. Leishmania testing is not mandatory in blood banks in Brazil but knowledge of positive serology would impose blood elimination. Since VL is expanding and control measures are not efficient, a broader discussion is needed regarding the need to implement specific screening strategies and, possibly, the risk of Leishmania transmission by blood transfusion.

\section{Abbreviations}

ELISA: Enzyme-linked Immunosorbent Assay; IFAT: Immunofluorescence Antibody Test; ITS: Internal Transcribed Spacer; kDNA: Kinetoplastid DNA; PCR: Polymerase chain reaction; SLA: Soluble Leishmania Antigen; VL: Visceral Leishmaniasis.

\section{Competing interests}

The authors declare they have no competing interests.

\section{Authors' contributions}

KFF, FSC and JRC performed experiments and analyzed results. AB, MBN, CIO and VF analyzed results. KFF, VF, MBN and $\mathrm{ClO}$ wrote the manuscript. All authors read and approved the final manuscript.

\section{Acknowledgments}

This work was supported by grants from FIOCRUZ and CNPq. KFF was a recipient of a CAPES fellowship. FSC was a recipient of a PIBIC/FIOCRUZ fellowship. $A B, M B N$ and $\mathrm{ClO}$ are senior investigators from CNPq.

\section{Author details}

'Centro de Pesquisas Gonçalo Moniz, Fundação Oswaldo Cruz (FIOCRUZ), Rua Waldemar Falcão, 121, Salvador, BA, Brazil. ${ }^{2}$ Fundação de Hematologia e Hemoterapia da Bahia (HEMOBA/SESAB), Av. Vasco da Gama, s/n, Salvador, BA, Brazil. ${ }^{3}$ Instituto de Investigação em Imunologia, Salvador, BA, Brazil.

Received: 26 February 2014 Accepted: 24 July 2014

Published: 30 July 2014

\section{References}

1. Leishmaniasis. http://www.who.int/leishmaniasis,

2. Romero GA, Boelaert M: Control of visceral leishmaniasis in latin america-a systematic review. PLoS Negl Trop Dis 2010, 4(1):e584.

3. Lainson R, Shaw Jj: Epidemiology and ecology of leishmaniasis in latinAmerica. Nature 1978, 273(5664):595-600.

4. Harhay MO, Olliaro PL, Costa DL, Costa CH: Urban parasitology: visceral leishmaniasis in Brazil. Trends Parasitol 2011, 27(9):403-409.

5. Michel G, Pomares C, Ferrua B, Marty P: Importance of worldwide asymptomatic carriers of leishmania infantum (L. chagasi) in human. Acta Trop 2011, 119(2-3):69-75
6. (WHO) WHO: Leishmaniasis. Fact sheet 2013, n.375. http://www.who.int/ mediacentre/factsheets/fs375/en/

7. Kubar J, Quaranta JF, Marty P, Lelievre A, Le Fichoux Y, Aufeuvre JP: Transmission of L. infantum by blood donors. Nat Med 1997, 3(4):368.

8. Cardo LJ: Serological screening for Leishmania infantum in asymptomatic blood donors living in an endemic area (Sicily, Italy). Transfus Apher Sci 2006, 34(2):233-234.

9. Riera C, Fisa R, Lopez-Chejade P, Serra T, Girona E, Jimenez M, Muncunill J, Sedeno M, Mascaro M, Udina M, Gállego M, Carrió J, Forteza A, Portús M: Asymptomatic infection by Leishmania infantum in blood donors from the Balearic Islands (Spain). Transfusion 2008, 48(7):1383-1389.

10. Dey A, Singh S: Transfusion transmitted leishmaniasis: a case report and review of literature. Indian J Med Microbio/ 2006, 24(3):165-170.

11. Huda MM, Rudra S, Ghosh D, Bhaskar KR, Chowdhury R, Dash AP, Bhattacharya SK, Haque R, Mondal D: Low prevalence of Leishmania donovani infection among the blood donors in kala-azar endemic areas of Bangladesh. BMC Infect Dis 2013, 13:62.

12. Ates SC, Bagirova M, Allahverdiyev AM, Baydar SY, Koc RC, Elcicek S, Abamor ES, Oztel ON: Detection of antileishmanial antibodies in blood sampled from blood bank donors in Istanbul. Future Microbio/ 2012, 7(6):773-779.

13. Cruz I, Morales MA, Noguer I, Rodriguez A, Alvar J: Leishmania in discarded syringes from intravenous drug users. Lancet 2002, 359(9312):1124-1125.

14. Cohen C, Corazza F, De Mol P, Brasseur D: Leishmaniasis acquired in Belgium. Lancet 1991, 338(8759):128.

15. Cummins D, Amin S, Halil O, Chiodini PL, Hewitt PE, Radley-Smith R: Visceral leishmaniasis after cardiac surgery. Arc Dis Child 1995, 72(3):235-236.

16. Basset D, Faraut F, Marty P, Dereure J, Rosenthal E, Mary C, Pratlong F, Lachaud L, Bastien P, Dedet JP: Visceral leishmaniasis in organ transplant recipients: 11 new cases and a review of the literature. Microbes Infect 2005, 7(13):1370-1375.

17. Mpaka MA, Daniil Z, Kyriakou DS, Zakynthinos E: Septic shock due to visceral leishmaniasis, probably transmitted from blood transfusion. $J$ Infect Dev Ctries 2009, 3(6):479-483.

18. Oliveira RA, Silva LS, Carvalho VP, Coutinho AF, Pinheiro FG, Lima CG, Leandro JE Jr, Silva GB Jr, Daher EF: Visceral leishmaniasis after renal transplantation: report of 4 cases in northeastern Brazil. Transpl Infect Dis 2008, 10(5):364-368.

19. Luz KG, da Silva VO, Gomes EM, Machado FC, Araujo MA, Fonseca HE, Freire TC, D'Almeida JB, Palatnik M, Palatnik-de Sousa CB: Prevalence of antiLeishmania donovani antibody among Brazilian blood donors and multiply transfused hemodialysis patients. Am J Trop Med Hyg 1997, 57(2):168-171.

20. Otero AC, da Silva VO, Luz KG, Palatnik M, Pirmez C, Fernandes O, de Sousa CB P: Short report: occurrence of Leishmania donovani DNA in donated blood from seroreactive Brazilian blood donors. Am J Trop Med Hyg 2000, 62(1):128-131.

21. França Ade O, de Castro VL, Lima MS Jr, Pontes ER, Dorval ME: Antileishmania antibodies in blood donors from the Midwest region of Brazil. Transfus Apher Sci 2013, 49:627-630.

22. DATASUS: Leishmaniose viscceral - casos confirmados notificados no sistema de informação de agravos de notificação - sinan net. http://dtr2004.saude.gov.br/sinanweb/tabnet/dh?sinannet/leishvi/bases/ leishvbrnet.def.

23. Castilho TM, Shaw JJ, Floeter-Winter LM: New PCR assay using glucose-6phosphate dehydrogenase for identification of Leishmania species. J Clin Microbiol 2003, 41(2):540-546.

24. Cupolillo E, Grimaldi Junior G, Momen H, Beverley SM: Intergenic region typing (IRT): a rapid molecular approach to the characterization and evolution of Leishmania. Mol Biochem Parasitol 1995, 73(1-2):145-155.

25. Rodgers MR, Popper SJ, Wirth DF: Amplification of kinetoplast DNA as a tool in the detection and diagnosis of Leishmania. Exp Parasitolo 1990, 71(3):267-275.

26. Lima ID, Queiroz JW, Lacerda HG, Queiroz PV, Pontes NN, Barbosa JD, Martins DR, Weirather JL, Pearson RD, Wilson ME, Jeronimo SMB: Leishmania infantum chagasi in northeastern Brazil: asymptomatic infection at the urban perimeter. Am J Trop Med Hyg 2012, 86(1):99-107.

27. Boaventura VS, Cafe V, Costa J, Oliveira F, Bafica A, Rosato A, de Freitas LA, Brodskyn C, Barral-Netto M, Barral A: Concomitant early mucosal and cutaneous leishmaniasis in Brazil. Am J Trop Med Hyg 2006, 75(2):267-269.

28. Saúde MD: Leishmaniose visceral: recomendações clínicas para redução da letalidade. In Série A Normas e Manuais Técnicos. Edited by Epidemiológica. BMdSSdVeSDdV. Brasília: Ministério da Saúde; 2011:78. 
29. de Oliveira Cl, Bafica A, Oliveira F, Favali CB, Correa T, Freitas LA, Nascimento E, Costa JM, Barral A: Clinical utility of polymerase chain reaction-based detection of Leishmania in the diagnosis of American cutaneous leishmaniasis. Clin Infect Dis 2003, 37(11):e149-e153.

30. Castilho TM, Camargo LM, McMahon-Pratt D, Shaw JJ, Floeter-Winter LM: A real-time polymerase chain reaction assay for the identification and quantification of American Leishmania species on the basis of glucose-6phosphate dehydrogenase. Am J Trop Med Hyg 2008, 78(1):122-132.

31. Evans TG, Teixeira MJ, Sousa Ade Q, Pearson RD: Short report: extended follow-up of the natural history of persons infected with Leishmania chagasi. Am J Trop Med Hyg 1995, 53(4):360-361.

32. Badaro R, Jones TC, Carvalho EM, Sampaio D, Reed SG, Barral A, Teixeira R, Johnson WD Jr: New perspectives on a subclinical form of visceral leishmaniasis. J Infect Dis 1986, 154(6):1003-1011.

33. Urias EVR, Carvalho SFG, Preval Oliveira CL, Carvalho MLM, Teles LF, Rodrigues MC, Maia CN: Leishmania chagasieishmania species on the basis of glucose-6-phosphate de. Rev Bras Hematol Hemoter 2009, 31:348-354.

34. Costa CH, Stewart JM, Gomes RB, Garcez LM, Ramos PK, Bozza M, Satoskar A, Dissanayake S, Santos RS, Silva MR, Shaw JJ, David JR, Maguire JH: Asymptomatic human carriers of Leishmania chagasi. Am J Trop Med Hyg 2002, 66(4):334-337.

35. Moreno EC, Melo MN, Lambertucci JR, Serufo JC, Andrade AS, Antunes CM, Genaro O, Carneiro M: Diagnosing human asymptomatic visceral leishmaniasis in an urban area of the State of Minas Gerais, using serological and molecular biology techniques. Rev Soc Bras Med Trop 2006, 39(5):421-427

36. Orsini M, Canela JR, Disch J, Maciel F, Greco D, Toledo A Jr, Rabello A: High frequency of asymptomatic Leishmania spp. infection among HIVinfected patients living in endemic areas for visceral leishmaniasis in Brazil. Trans R Soc Trop Med Hyg 2012, 106(5):283-288.

37. Clemente WT, Rabello A, Faria LC, Peruhype-Magalhaes V, Gomes LI, da Silva TA, Nunes RV, lodith JB, Protil KZ, Fernandes HR, Cortes JR, Lima SS, Lima AS, Romanelli RM: High prevalence of asymptomatic Leishmania spp. infection among liver transplant recipients and donors from an endemic area of Brazil. Am J Transplant 2014, 14(1):96-101.

38. Lachaud L, Dereure J, Chabbert E, Reynes J, Mauboussin JM, Oziol E, Dedet JP, Bastien P: Optimized PCR using patient blood samples for diagnosis and follow-up of visceral Leishmaniasis, with special reference to AIDS patients. J Clin Microbiol 2000, 38(1):236-240

39. Mary C, Faraut F, Drogoul MP, Xeridat B, Schleinitz N, Cuisenier B, Dumon H: Reference values for Leishmania infantum parasitemia in different clinical presentations: quantitative polymerase chain reaction for therapeutic monitoring and patient follow-up. Am J Trop Med Hyg 2006, 75(5):858-863.

40. dos Santos Marques LH, Gomes LI, da Rocha IC, da Silva TA, Oliveira E, Morais MH, Rabello A, Carneiro M: Low parasite load estimated by qPCR in a cohort of children living in urban area endemic for visceral leishmaniasis in Brazil. PLoS Negl Trop Dis 2012, 6(12):e1955.

41. le Fichoux Y, Quaranta JF, Aufeuvre JP, Lelievre A, Marty P, Suffia I, Rousseau $D$, Kubar J: Occurrence of Leishmania infantum parasitemia in asymptomatic blood donors living in an area of endemicity in southern France. J Clin Microbiol 1999, 37(6):1953-1957.

42. Martin-Sanchez J, Pineda JA, Morillas-Marquez F, Garcia-Garcia JA, Acedo C, Macias J: Detection of Leishmania infantum kinetoplast DNA in peripheral blood from asymptomatic individuals at risk for parenterally transmitted infections: relationship between polymerase chain reaction results and other Leishmania infection markers. Am J Trop Med Hyg 2004, 70(5):545-548.

43. Scarlata F, Vitale F, Saporito L, Reale S, Vecchi VL, Giordano S, Infurnari L, Occhipinti F, Titone L: Asymptomatic Leishmania infantum/chagasi infection in blood donors of western Sicily. Tran R Soc Trop Med Hyg 2008, 102(4):394-396.

44. Carranza-Tamayo CO, de Assis TS, Neri AT, Cupolillo E, Rabello A, Romero GA: Prevalence of Leishmania infection in adult HIV/AIDS patients treated in a tertiary-level care center in Brasilia, Federal District, Brazil. Tran R Soc Trop Med Hyg 2009, 103(7):743-748.

45. Bastien P, Procop GW, Reischl U: Quantitative real-time PCR is not more sensitive than "conventional" PCR. J Clin Microbiol 2008, 46(6):1897-1900.

46. Oliveira JG, Novais FO, de Oliveira Cl, da Cruz Junior AC, Campos LF, da Rocha AV, Boaventura V, Noronha A, Costa JM, Barral A: Polymerase chain reaction $(P C R)$ is highly sensitive for diagnosis of mucosal leishmaniasis. Acta Trop 2005, 94(1):55-59.

47. Palatnik-de-Sousa CB, Paraguai-de-Souza E, Gomes EM, Soares-Machado FC, Luz KG, Borojevic R: Transmission of visceral leishmaniasis by blood transfusion in hamsters. Braz J Med Biol Res 1996, 29(10):1311-1315.

48. Owens SD, Oakley DA, Marryott K, Hatchett W, Walton R, Nolan TJ, Newton A, Steurer F, Schantz P, Giger U: Transmission of visceral leishmaniasis through blood transfusions from infected English foxhounds to anemic dogs. J Vet Med Educ 2001, 219(8):1076-1083.

doi:10.1186/1471-2334-14-422

Cite this article as: Fukutani et al.: Serological survey of Leishmania infection in blood donors in Salvador, Northeastern Brazil. BMC Infectious Diseases 2014 14:422.

\section{Submit your next manuscript to BioMed Central and take full advantage of:}

- Convenient online submission

- Thorough peer review

- No space constraints or color figure charges

- Immediate publication on acceptance

- Inclusion in PubMed, CAS, Scopus and Google Scholar

- Research which is freely available for redistribution

Submit your manuscript at www.biomedcentral.com/submit
C) Biomed Central 